\title{
BATUAN LOKAL PACITAN (DRUZY) DALAM PENCIPTAAN PERHIASAN PERAK INOVATIF
}

\author{
Alvi Lufiani *)
}

\begin{abstract}
ABSTRACK
The creation of innovative jewelry using local gem stone Pacitan (Druzy) is considered to be essential in addition to introduce Indonesia's natural wealth in the form of jewelry and also shows that the local gem stone can look elegant, high qualified and taste globally if we can mix and match it with other appropriate supporting material and innovative design .

The method used in the creation of innovative jewelry using this Druzy stone is a method of exploration, experimentation and the materialization according to the stage in the creation of craft art.

Contribution that can be given in the creation of silver jewelry by utilizing local gem stone are able to increase the awareness of Indonesia people that a lot of potential natural wealth around us that still unprocessed wisely and creatively. If the ability to process the natural wealth is more refined, it will create a lot of local jewelry products that has world-class quality. In addition, those innovative jewelry products would enrich the world of art jewelry in Indonesia and speaks at the international level bringing the identity and culture of the nation.
\end{abstract}

Key words: Silver jewelry, innovative, Druzy local gemstone

\begin{abstract}
ABSTRAK
Penciptaan perhiasan inovatif dengan menggunakan batuan local Pacitan (druzy) ini dirasa penting selain untuk lebih memperkenalkan kekayaan alam Indonesia dalam bentuk perhiasan juga untuk menunjukan bahwa batuan local dapat tampil elegan, berkelas dan bercita rasa global apabila kita dapat memadu padankannya dengan material pendukung lain yang tepat dengan desain yang inovatif.

Metode yang digunakan dalam penciptaan perhiasan inovatif dengan menggunakan batu druzy ini adalah metode eksplorasi, eksperimen dan perwujudan sesuai dengan tahap penciptaan dalam seni kriya.

Kontribusi yang dapat diberikan dalam penciptaan perhiasan perak dengan memanfaatkan batuan local ini adalah dapat semakin meningkatkan kesadaran masyarakat luas Indonesia bahwa banyak sekali potensi alam yang ada di sekitar kita yang belum diolah secara bijak dan kreatif. Apabila kemampuan mengolah tersebut semakin terasah, maka akan
\end{abstract}

\footnotetext{
* Alvi Luviani, Staf Pengajar Program Studi Kriya Seni, Jurusan Kriya, Fakultas Seni Rupa, Institut Seni Indonesia Yogyakarta
} 
banyak sekali tercipta produk perhiasan bermuatan local dengan cita rasa global. Selain itu karya perhiasan inovatif ini mampu memperkaya khasanah dunia seni perhiasan di Indonesia sekaligus berbicara di kancah internasional tanpa meninggalkan jati diri dan budaya bangsa.

Kata kunci: Perhiasan perak, inovatif, batuan local Druzy

\section{PENDAHULUAN}

Pemanfaatan material alam dalam pembuatan perhiasan sudah dilakukan oleh manusia sejak jaman lampau. Tidak terhitung lagi berapa banyak produk kerajinan, fesyen, home furnishing dan aksesories atau perhiasan yang mengekplorasi unsur alam sebagai materialnya. Khusus untuk perhiasan, manusia bahkan sudah menciptakan perhiasan dari tulang belulang sejak jaman purba. Seiring dengan berjalannya waktu dan kepandaian manusia dalam mengolah bahan untuk menciptakan perhiasan, maka semakin bervariasi pula jenis bahan yang digunakan. Contohnya adalah kerang, batubatuan, fosil kayu, kayu serta logam. Menariknya pada era prasejarah perhiasan yang terbuat dari kerang, batu dan tulang merupakan sebuah proteksi dari ancaman bahaya sekaligus sebagai penanda status social (www.vam.ac.uk).

$$
\text { Penggunaan batuan berharga }
$$

semakin intensif terjadi pada era Renaissance yang ditandai dengan teknik pemotongan (cutting) yang semakin baik sehingga menambah kecemerlangan batuan tersebut. Bahkan, banyak perhiasan spektakuler yang dipakai untuk menunjukkan kekuatan politik serta keutamaan dari agama tertentu. Kesadaran artistik dari individu tentang perhiasan juga semakin tampak. Sampai pada abad
17, perubahan pada fashion juga memengaruhi perkembangan perhiasan. Ditambah lagi dengan perdagangan dunia yang semakin luas sehingga memudahkan orang untuk mendapatkan aneka bebatuan.

Hal menarik yang perlu dicermati pada era ini adalah mulai maraknya perhiasan dengan desain naturalistik seperti bunga dan buah-buahan. Bunga diasosiasikan dengan pertemanan dan cinta. Warna-warna alam direpresentasikan pada bebatuan yang dipakai dan dianggap dapat menyampaikan pesan tertentu. Pada jaman ini, perhiasan lebih banyak dikenakan oleh perempuan. Begitulah sedikit sejarah tentang perhiasan, sampai pada akhirnya kita juga mengenal perhiasan era Art Nouveau, Art Deco, dan kontemporer.

Di Indonesia, penggunaan bebatuan, khususnya bebatuan mulia banyak dipergunakan oleh kaum bangsawan atau keluarga kerajaan. Khusus untuk raja dan ratu, perhiasan yang dibuat harus taat pada peraturan yang berlaku sampai pada hal yang amat detil seperti jumlah, jenis, warna, dan ukuran batuan mulia yang dipakai. Alasannya karena bebatuan tersebut mempunyai aura magis tertentu yang tidak boleh diterapkan secara sembarangan.

Carnelian, ruby, haematite, emerald, intan, amethyst dan topaz adalah 
jenis bebatuan semi mulia (semi precious stone) yang paling banyak dipakai oleh kerajaan-kerajaan Nusantara pada era abad ke-18 hingga 19. Tercatat diantaranya adalah kerajaan Gowa di Sulawesi Selatan, Samudera Pasai, Aceh, Kutai di Kalimantan dan Pagaruyung di Sumatera Barat. Bentuk atau desain yang diterapkan beraneka ragam, mulai dari motif geometris, adaptasi flora, dan fauna. Motif fauna lebih sedikit dipakai mengingat kerajaaankerajaan Nusantara tersebut sudah banyak yang mengadopsi nilai ajaran Islam untuk tidak menggunakan makhluk hidup bernyawa dalam produk apapun yang mereka ciptakan. (Carpenter, 2011, 447).

Batu druzy, sebagai material utama penciptaan perhiasan perak kali ini merupakan batuan alam yang banyak terdapat di daerah pegunungan di kabupaten Pacitan, Jawa Timur. Batu ini memiliki kekerasan 6-7 skala Mohs dan kandungan silica yang mengkristal di dalam membuatnya menjadi keras. Druzy terdapat pada batuan jenis kwarsa, dengan ukuran yang bervariasi. Mulai dari bongkahan kecil hingga berukuran medium dengan kristal renik yang berkilau bila terkena sinar lampu maupun matahari. Keunikan lainnya adalah adanya lubang di tengah atau kikisan batu yang tidak teratur yang semakin membuat druzy terlihat berbeda dan mewah. (Setia Graha, 1987, 253).

Pacitan sendiri dikenal dengan daerahnya yang tandus dan gersang. Kabupaten Pacitan terdiri dari daerah pegunungan dan berbukit-bukit, juga wilayahnya termasuk kawasan karst. Sedangkan selebihnya merupakan dataran rendah. Sekitar 63\% dari daerah Pacitan adalah daerah yang berfungsi penting untuk hidrologis karena memiliki tingkat kemiringan lebih $40 \%$. Berdasarkan ciri-ciri fisik tanahnya, Kabupaten Pacitan adalah bagian dari pegunungan kapur selatan yang bermula dari Gunung Kidul, Yogyakarta dan membujur sampai ke daerah Trenggalaek yang relative tanahnya tandus.

Daerah pegunungan dan sungai di perbukitan Pacitan merupakan sumber berbagai jenis batu Agate, Chalcedony, Onyx, Sardonyx, Jasper, Carnelian dan lainnya. Batu natural crystal dari daerah ini juga lumayan besar dan bening, sama halnya dengan batuan druzy yang amat beraneka bentuknya. (http://javagemstone.blogspot.com).

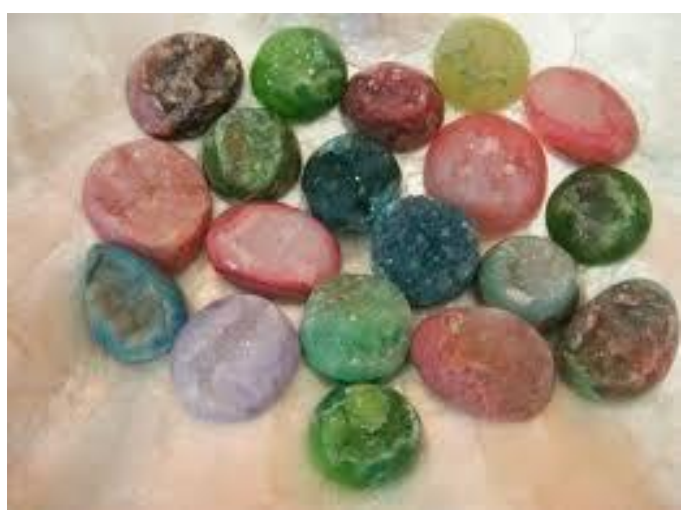

Gb.1. Contoh batu Druzy aneka warna

Ketertarikan penulis untuk mengolah druzy menjadi perhiasan karena melihat kenyataan bahwa perhiasan druzy yang ada di pasaran selama ini terlihat kurang menarik karena desain yang itu-itu saja dan kurang mampu mengekspos karakter lokal dan keindahan natural dari batu tersebut. Sebenarnya dengan adanya sentuhan lokal yaitu menerapkan motif tradisional dipadukan keunikan serta keindahan yang dimiliki oleh batu druzy, hanya diperlukan sedikit saja polesan 
untuk dapat menghasilkan perhiasan yang elegan dan atraktif.

Beberapa manfaat yang akan didapat dari penciptaan perhiasan inovatif menggunakan batu druzy adalah semakin dikenalnya batu druzy oleh masyarakat luas, serta menunjukkan bahwa batuan lokal yang banyak terdapat di Pacitan ini memiliki potensi yang luar biasa apabila mampu mengolahnya menjadi sebuah perhiasan atraktif, baik dari segi bentuk maupun visualisasinya. Batuan lokal mampu menjelma menjadi perhiasan berkualitas global.

Metode Penelitian/Penciptaan

Menurut Sp. Gustami dalam bukunya Butir-Butir Mutiara Estetika Timur dikatakan bahwa proses penciptaan seni kriya dapat ditempuh melalui metode ilmiah yang direncanakan secara seksama, analitis dan sistematis. Dalam konteks metodologis, terdapat tiga tahap penciptaan seni kriya, yaitu eksplorasi, perancangan dan perwujudan (Gustami, 2007, 329). Dalam penciptaan perhiasan dari batuan druzy kali ini metode penciptaan yang dilakukan adalah sebagai berikut.

\section{Metode Eksplorasi}

Metode ini dilakukan dengan melakukan kunjungan ke berbagai pameran perhiasan atau pameran objekobjek tiga dimensional, melakukan pencarian data, baik visual maupun teks di perpustakaan dan internet untuk mencari informasi dan gambaran sebanyakbanyaknya terkait dengan karya yang akan diciptakan serta diskusi dengan pihak-pihak yang berkompeten. Setelah semua informasi dan data terkumpul, barulah dilakukan evaluasi untuk menyeleksi karya mana yang paling baik digunakan sebagai acuan. Eksplorasi dilakukan dengan berbagai pengamatan dan berbagai sudut. Mulai dari eksplorasi ide, material, bentuk, teknik, dan finishing.

\section{Metode Eksperimen}

Eksperimen akan dilakukan dari proses awal proses akhir. Eksperimen alam hal pembuatan bentuk (form) karya. Eksperimen dalam hal menentukan bahan material yang digunakan, maksudnya pencipta harus bisa menentukan material mana yang terbaik karena mempertimbangkan tingkat kesulitan karya. Eksperimen terhadap proses dan teknik yang dipandang cocok untuk dipakai dan eksperimen terhadap penyelesaian kerja akhir (finishing), yakni mencari kemungkinan-kemungkinan finishing akhir yang terbaik.

\section{PEMBAHASAN}

Seperti yang sudah dibahas dalam latar belakang di atas, hampir seluruh negara di dunia memiliki banyak pengrajin maupun desainer perhiasan yang kerap memanfaatkan batuan alam dalam menciptakan karya perhiasan yang atraktif dan inovatif. Dari dalam negeri sendiri ada seorang desainer yang cukup fenomenal. Karya-karya perhiasannya dikenakan oleh mulai dari ibu negara Ani Yudoyono, menteri pariwisata dan industri kreatif Mari Elka pangestu sampai artis-artis kaliber dan sosialita Holywood seperti Sharon Stone, Michele Yeoh dan 
Muhammad Al-Fayed, pemilik pertokoan elit Harrods di Inggris.

Karya Delia von Rueti dikatakan fenomenal karya sangat memperhatikan detil dan mampu mengolah batu-batuan alam yang orang tidak terpikirkan sebelumnya menjadi karya perhiasan yang luar biasa dan berkarakter kuat, sering disebut "one of a kind and signature works of jewelry art". Selain itu ukuran yang dipakai juga tidak umum, yaitu cukup besar namun tetap indah dan memiliki nilai artisitik tinggi. Tidak lupa Delia selalu berusaha memadu padankan perhiasannya dengan ciri khas Indonesia tetapi pada kenyataannya mampu menembus pasar internasional (www.deliavonrueti.com).

\section{PROSES PERWUJUDAN KARYA}

\begin{tabular}{lll}
\multicolumn{2}{c}{ Pembuatan karya perhiasan } \\
berbahan tekstil ini melalui beberapa \\
tahapan yang telah dilalui. Tahapan-
\end{tabular} tahapan tersebut dimulai dengan adanya riset atau studi pustaka atau visual yang dilakukan dengan melihat dan membaca berbagai macam referensi yang berkaitan dengan perhiasan perak terbaru dengan memakai batu alan khususnya druzy. Referensi yang didapat tentang penggunaan batuan druzy dalam perhiasan memang cukup banyak, namun sayangnya yang sesuai dengan konsep inovatif dan bercita rasa global seperti yang peneliti inginkan tidak atau kurang jumahnya, sehingga hampir seluruh desain yang peneliti buat merupakan ide atau kreasi pribadi dari pencipta. Adapun bahan atau referensi yang ada didapatkan tidak hanya melalui buku melainkan juga internet, majalah, postcard, catalog, dan sumber lain yang sejenis.
Setelah didapat cukup data yang memadai untuk keperluan penciptaan karya, mulailah dibuat beberapa desain. Desain-desain tersebut dibuat sebanyak mungkin karena setelah itu akan dilakukan proses seleksi, mana desain yang cocok dan mana yang tidak. Tentu saja desain yang cocoklah yang akan diwujudkan menjadi karya perhiasan.

Proses perwujudan karya perhiasan dapat dimulai setelah material atau bahan dan alat-alat yang akan digunakan sudah siap semuanya. Langkahlangkah proses perwujudannya adalah sebagai berikut.

1. Pertama-tama kita menyiapkan lembaran logam/ plat untuk membungkus batu (bezel stone) dan melingkarkannya pada batu, beri tanda dan potong. Untuk batu yang kecil tekuk dengan alat dan dipaskan dengan ukuran batu.

2. Bersihkan ujung logam yang akan disolder agar permukaannya rata. Gunakan solder sesedikit mungkin karena apabila terlalu banyak akan kencang dan kurang flexible pada saat akan memasukkan batu.

3. Setelah disolder, cek ukuran bezel. Apabila terlalu kecil diperbesar dengan dibentuk memakai ring size, tapi apabila terlalu besar maka harus disolder lagi dengan menghilangkan solder yang sudah ada untuk memperkecilnya.

4. Amplas atau kikir permukaan bezel untuk mendapatkan permukaan yang rata dan sesuai yang diinginkan.

5. Solder bezel pada permukaan logam yang rata, bersihkan dan pastikan sudah tersambung dengan baik. Bezel 
benar-benar harus lekat pada logam dengan sempurna.

6. Setelah bezel menempel sempurna pada logam, buang kelebihan logam dengan menggergaji atau mengguntingnya.

7. Solder bezel pada posisi yang diinginkan.

8. Untuk bros, bezel yang sudah menempel pada logam ditambahkan dengan kawat yang sudah dibentuk sesuai ornamen yang diinginkan. Pemakaian kawat ini dikenal juga dengan istilah filigri/filigree. Kawat tersebut disolder dengan bagian bezel.

9. Setelah bezel terangkai dengan hiasan kawat (filigri) batu yang ada siap untuk dimasukkan.

10. Finishing touch perhiasan batu druzy dilakukan dengan mengampelas, mengikir dan memoles (polishing) dengan gerinda. Finishing touch harus dilakukan dengan hati- hati agar jangan sampai merusak batu.
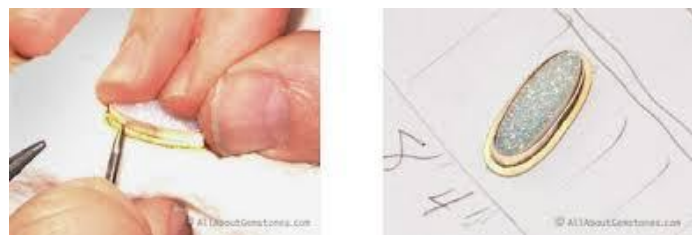

Gb.2. llustrasi proses merapikan (mengikir bezel).

Gb.3. Bezel yang sudah diisi batu

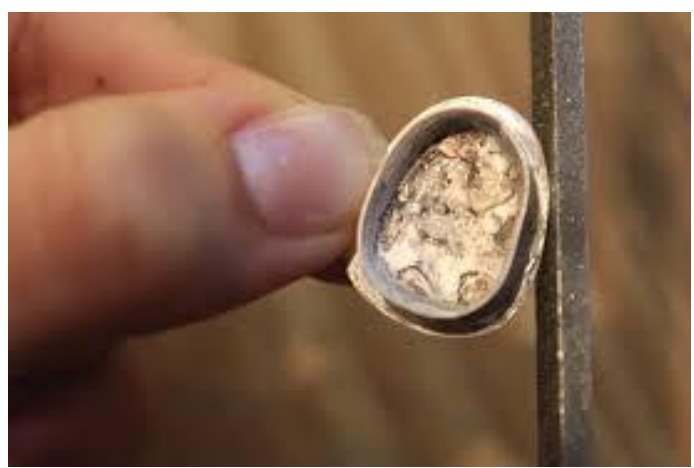

Gb.4. Proses pengikiran pinggiran bezel

\section{FOTO HASIL KARYA CIPTAAN}

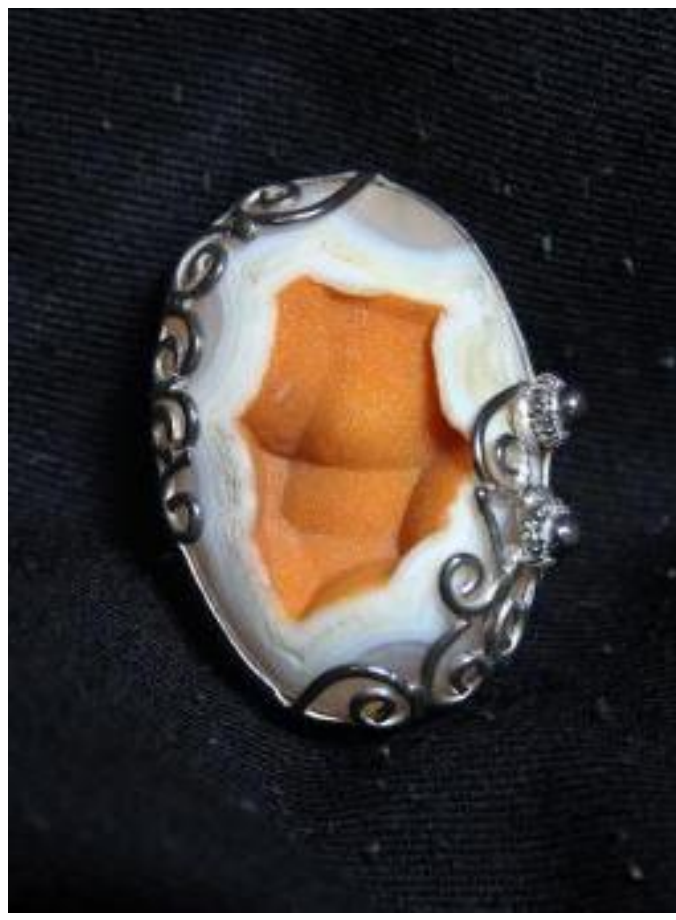

Gb.5. Bros Druzy dengan filigri

$3 \times 2,4 \times 1 \mathrm{~cm}$, sterling silver,

batu druzy, 2014

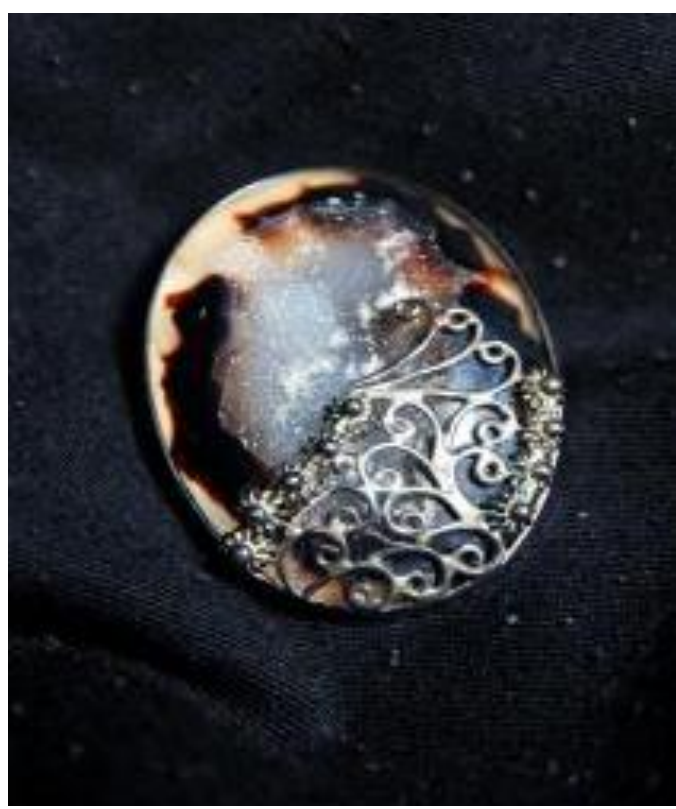

Gb.6. Bros Druzy dengan filigri $3,5 \times 3,7 \times 1 \mathrm{~cm}$, sterling silver, batu druzy, 2014 


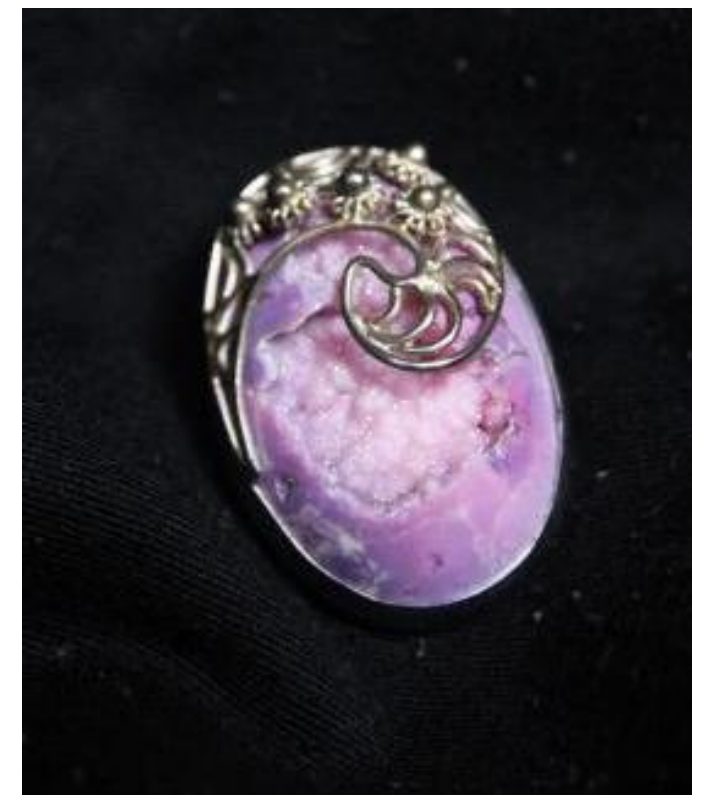

Gb.7. Bros druzy dengan filigri $4 \times 2,8 \times 1,7 \mathrm{~cm}$

sterling silver, batu druzy, 2014

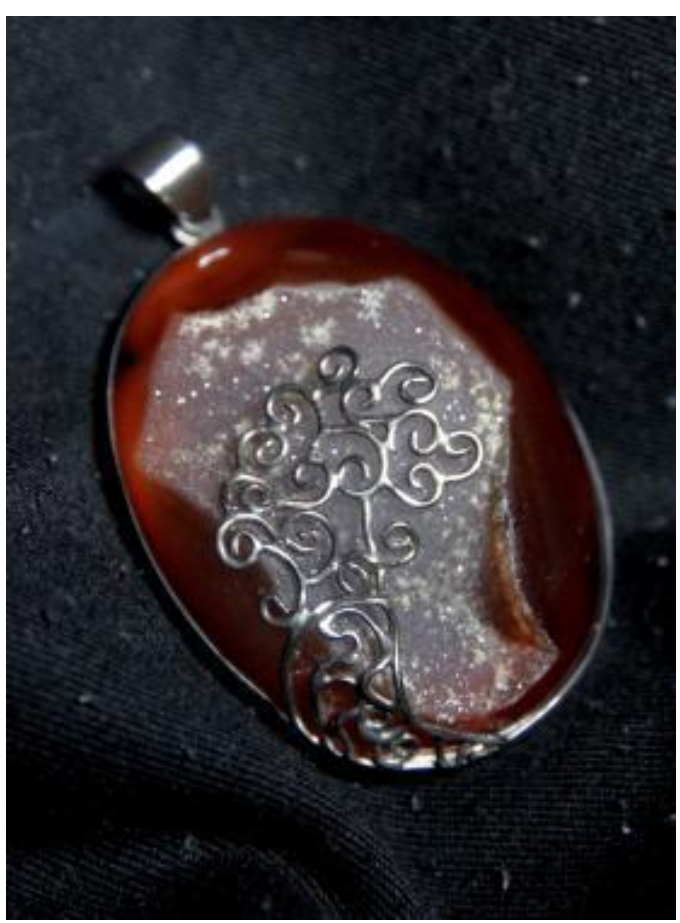

Gb.8. Liontin druzy dengan filigri $4,5 \times 3,5 \times 1,3 \mathrm{~cm}$

sterling silver, batu druzy, 2014

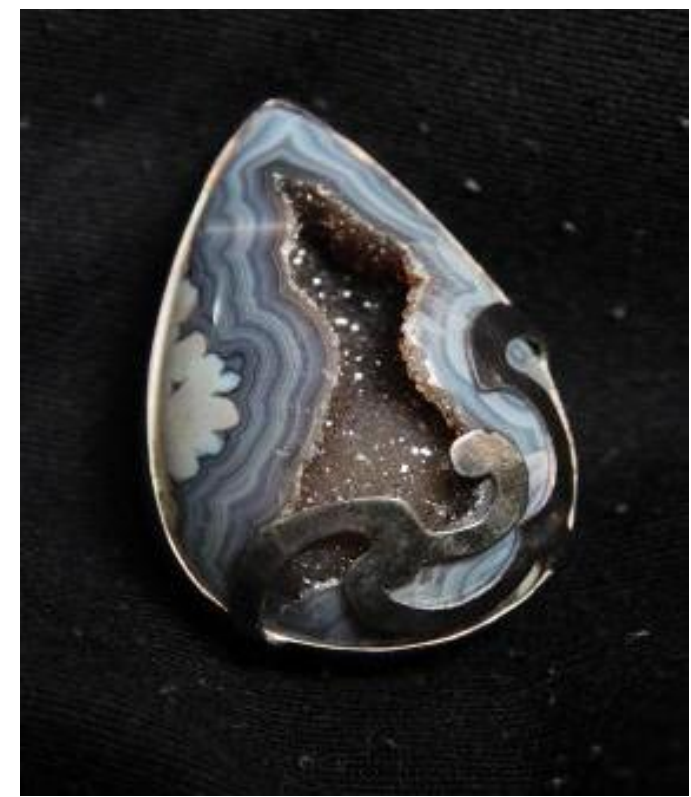

Gb.9. Liontin druzy

$4 \times 2,5 \times 1,7 \mathrm{~cm}$

sterling silver, batu druzy, 2014

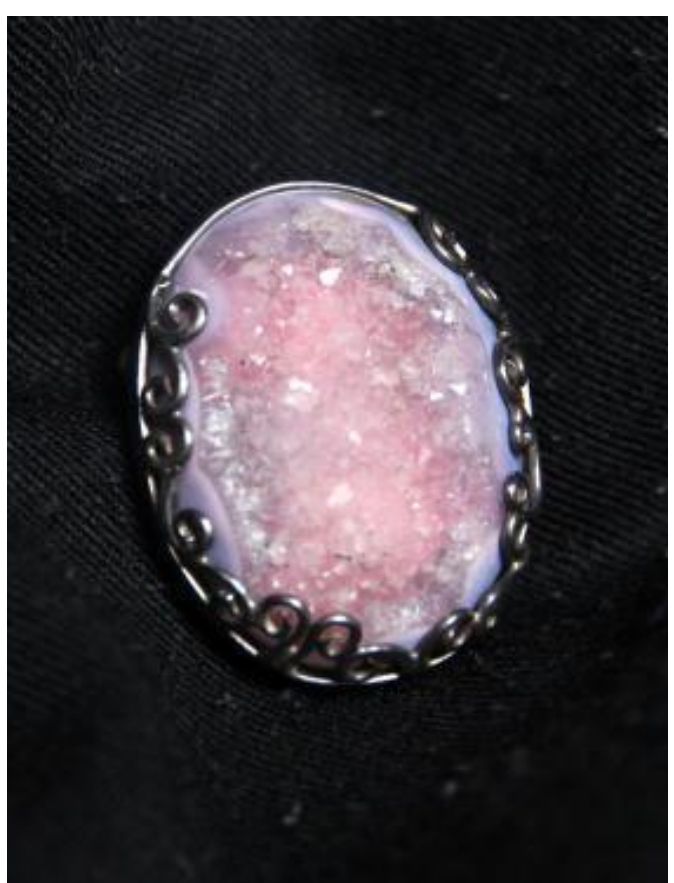

Gb.10. Bros druzy dengan filigri $2 \times 3 \times 0,8 \mathrm{~cm}$

sterling silver, batu druzy, 2014 


\section{PENUTUP}

\begin{abstract}
Kesimpulan yang didapat dari proses penciptaan inovatif berbahan utama batuan local Pacitan (druzy) ini adalah terbukti bahwa batu druzy sebagai batuan local apabila dipadukan dengan desain yang menarik dapat menjadi sebuah karya perhiasan yang elegan, atraktif serta eksklusif. Dalam penelitian kali ini pencipta menggunakan material perak sterling (sterling silver) berkadar 925 sebagai pengikat batu druzy tersebut. Penting
\end{abstract} untuk dipahami bahwa ada beberapa elemen yang harus diperhatikan untuk mendapatkan hasil tersebut, yaitu perlu pemilihan batu druzy secara jeli karena banyak sekali jenis batu druzy yang ada di pasaran, terutama dari warnanya. Sebagian warna ada yang amat menyolok sehingga terkesan murah dan tidak elegan. Untuk itulah kecermatan dalam memilih dan memilah amat vital. Selain dari pemilihan warna dan bentuk batu, tentu saja unsure yang amat penting adalah desain keseluruhan dari perhiasan tersebut.

Kesimpulan lainnya adalah salah satu cara memvisualisasikan atau merealisasikan perhiasan bercita rasa global dengan menggunakan batuan local dengan motif Indonesia adalah kita harus senantiasa up date dengan trend perhiasan dunia terkini untuk kemudian memadukannya dengan kekayaan atau identitas budaya bangsa yang kita miliki ini. Hal ini merupakan salah satu cara menjawab tantangan pasar global yang mau tidak mau harus kita hadapi agar dapat terus eksis.

Jenis perhiasan yang dihasilkan dari perpaduan motif tradisional Indonesia dengan batuan local (druzy) tersebut dalam penelitian ini adalah bros, liontin, bros-liontin (two in one) dan cincin. Alasan mengapa ketiga perhiasan tersebut yang dibuat adalah melihat kenyataan yang ada bahwa sebagian besar perempuan, baik yang karir atau non karir, utamanya yang menggunakan hijab mutlak membutuhkan bros dalam kesehariannya. Untuk itulah pencipta membuat lebih banyak bros dibanding jenis perhiasan lainnya, disusul liontin yang mudah dipadu padankan dengan kalung atau rantai serta cincin. Salah satu alasan lain megapa pencipta tidak menciptakan kalung per set dan gelang adalah sulitnya mencari batuan druzy dengan warna dan bentuk yang sama persis atau hampir sama untuk dijadikan set gelang atau kalung. Hal atau keunikan inilah yang tidak atau jarang dimiliki oleh jenis batuan lainnya. Masing-masing batu druzy selalu memiliki bentuk, karakter dan warna yang berbeda, walaupun berusaha dibentuk oleh pengrajin batu namun tetap sangat sulit untuk dihasilkan bentuk yang persis sama.

Saran yang ingin pencipta ingin sampaikan dalam penelitian kali ini adalah agar kegiatan penelitian atau penciptaan ini dapat terus diselenggarakan dan ditingkatkan kualitas maupun kuantitas pesertanya secara lebih baik, terutama dari segi penyediaan dananya. Apabila hal ini dapat tercapai, dapat dipastikan akan semakin menumbuhkan suasana berkreasi dan berpikir yang semakin kondusif dan membuahkan hasil yang bermanfaat tidak hanya bagi segenap civitas akademika ISI Yogyakarta, melainkan juga bagi masyarakat yang membutuhkan. Selain itu peran atau tanggung jawab dosen atau 
tenaga pengajar untuk senantiasa aktif melakukan penelitian (penciptaan) juga terus terasah sebagai bagian dair Tri Dharma Perguruan Tinggi.

\section{KEPUSTAKAAN}

Brus, Rene, (2011), Crown Jewelry and Regalia of the World, The Pepin Press, Amsterdam.

Drutt, Helen W. English, (1995), Jewelry of Our Time, Thames and Hudson Ltd, London.

Forty, Adrian, (2005), Object of Desire, Cameron Books, Dumfriesshire.

Game, Amanda and Elizabeth Goring, (2001), Jewelry Moves, MMS Publishing Ltd, Scotland.

Gustami, SP., (2007), Butir-Butir Mutiara Estetika Timur, Ide Dasar Penciptaan Seni Kriya Indonesia, Penerbit Prasista, Yogyakarta

Hamilton, W.R, (1975), The Hamlyn Guide to Minerals, Rocks and Fossils, The Hamlyn Publishing Group Ltd, London.

Lagomarsino, James, (2008), A Pocket Guide to Rocks and Minerals, Parragon Books Ltd, Bath.

May, Andrew, (1998), Indonesian Ornamental Design, The Pepin Press, Amsterdam and Kuala Lumpur.

Richer, Anne and Bruce W. Carpenter, (2011), Gold Jewellery of the Indonesia
Archipelago, Editions Didier Millet Pte Ltd, Singapore.

Rodgers, Susan, (1988), Jewelry from Indonesia, Malaysia and the Philippines, Prestel-Verlag, Munich.

Setia Graha, Doddy, (1987), Batuan dan Mineral, Penerbit Nova, Bandung.

\section{Webtografi}

www.vam.co.uk

www.deliavonrueti.cum

www.ucsilverbali.com 